\title{
LONG-TERM FOLLOW-UP OF A SINGLE CONTINUOUS ADJUSTABLE SUTURE IN PENETRATING KERATOPLASTY
}

\author{
PAUL B. CHELL, MONIQUE W. HOPE-ROSS, PETER SHAH and PETER J. McDONNELL \\ Birmingham
}

\begin{abstract}
SUMMARY
Penetrating keratoplasty was performed on 30 patients using a single adjustable continuous 10/0 nylon suture. Seventeen patients had astigmatism of 4.00 dioptre cylinders (DC) or more and were adjusted. The latest adjustment was at 32 weeks. Following adjustment there was a significant reduction in median postkeratoplasty astigmatism from 6.00 DC to $2.50 \mathrm{DC}$ $(p<0.001)$. Thirteen patients, with astigmatism of 4.00 DC or less, were not adjusted. Median astigmatism for the non-adjusted group was 3.00 DC and for the entire group was 2.88 DC. Long-term refraction and suture status were monitored with time. Mean follow-up was 112 weeks (range 53-170 weeks). Over the study period the entire group showed significant 'long-term astigmatic drift' (LTAD), from 2.88 DC to 3.25 DC (median drift, 1.25 DC; range, 0.00-5.50 DC) $(p<0.001)$. Suture adjustment and suture removal showed no significant effect on LTAD. With suture removal between 32 and 84 weeks median LTAD was 1.50 DC. For suture removal after 84 weeks, median LTAD was also 1.50 DC, but the range of LTAD was $1.50 \mathrm{DC}$, compared with a larger range of 5.00 DC in the earlier suture removal group. The technique of single continuous adjustable sutures for penetrating keratoplasty is safe, effective in reducing astigmatism, but may need modification to further enhance long-term refractive stability.
\end{abstract}

Penetrating keratoplasty is the accepted surgical procedure for improving visual function in eyes with severe corneal pathology. Astigmatism commonly follows surgery and may be severe in the postoperative period. High levels of astigmatism may profoundly affect outcome in otherwise successful grafts.

From: The Corneal Clinic, Birmingham and Midland Eye Hospital, Birmingham, UK.

Correspondence to: $\mathrm{Mr}$ P. J. McDonnell, MRCP, FRCS, FRCOphth, Birmingham and Midland Eye Hospital, Church Street, Birmingham B3 2NS, UK.
The control of astigmatism has proved a difficult problem for all surgeons performing penetrating keratoplasty. Even with modern surgical techniques astigmatism proves to be a major factor in both poor subjective and objective surgical outcome. The technique of suturing the graft employing a single adjustable continuous suture is well described. ${ }^{1}$ It allows the surgeon to adjust the suture postoperatively, is performed at the slit lamp at routine follow-up, and is eminently reversible. This technique has been shown dramatically to reduce astigmatism, a parameter so integral to satisfactory outcome. ${ }^{1-3}$

This study employs vector analysis to examine the long-term refractive stability and outcome of a consecutive series of patients who underwent penetrating keratoplasty using an adjustable single continuous suture.

\section{PATIENTS AND METHODS}

A prospective study was set up in the Corneal Clinic at the Birmingham and Midland Eye Hospital in October 1990. Thirty-nine consecutive patients with non-vascularised corneal pathology requiring penetrating keratoplasty were enrolled into the trial. One patient in the adjusted group in the original trial was lost to follow-up. Long-term follow-up of 30 patients is presented. There were 16 males and 14 females, aged from 15 to 90 years (mean 45 years), with

Table I. Diagnosis prior to penetrating keratoplasty in 30 nonvascularised corneas

\begin{tabular}{lc}
\hline Diagnosis & No. \\
\hline Fuchs' endothelial dystrophy & 4 \\
Herpetic keratitis & 1 \\
Keratoconus & 15 \\
Pseudophakic bullous keratopathy & 8 \\
Traumatic corneal scar & 2 \\
Total & 30 \\
\hline
\end{tabular}


Table II. Astigmatism following penetrating keratoplasty in 30 patients with time

\begin{tabular}{|c|c|c|c|c|c|c|c|}
\hline \multirow[b]{2}{*}{ Time } & \multicolumn{7}{|c|}{ Dioptre cylinder (DC) } \\
\hline & $\leqslant 1.00$ & $\leqslant 2.00$ & $\leqslant 3.00$ & $\leqslant 4.00$ & $\leqslant 5.00$ & $\leqslant 6.00$ & $>6.00$ \\
\hline \multicolumn{8}{|l|}{ Post-keratoplasty } \\
\hline Adjusted $(n=17)$ & 0 & 0 & 0 & 0 & 6 & 5 & 6 \\
\hline Non-adjusted $(n=13)$ & 3 & 1 & 5 & 3 & 1 & 0 & 0 \\
\hline Total $(n=30)$ & 3 & 1 & 5 & 3 & 7 & 5 & 6 \\
\hline \multicolumn{8}{|l|}{ Post-adjustment } \\
\hline Adjusted $(n=17)$ & 2 & 4 & 7 & 2 & 2 & 0 & 0 \\
\hline Non-adjusted $(n=13)$ & 3 & 1 & 5 & 3 & 1 & 0 & 0 \\
\hline Total $(n=30)$ & 5 & 5 & 12 & 5 & 3 & 0 & 0 \\
\hline \multicolumn{8}{|l|}{ Long-term review } \\
\hline Adjusted $(n=17)$ & 1 & 5 & 4 & 2 & 3 & 2 & 0 \\
\hline Non-adjusted $(n=13)$ & 1 & 3 & 1 & 4 & 1 & 1 & 2 \\
\hline Total $(n=30)$ & 2 & 8 & 5 & 6 & 4 & 3 & 2 \\
\hline
\end{tabular}

Initial astigmatism $(n=30)$ : $5.00 \mathrm{DC}$ (range 1.00-9.00 DC).

Post-adjustment astigmatism ( $n=30): 2.88 \mathrm{DC}$ (range 1.00-6.00 DC).

Final astigmatism $(n=30): 3.25$ DC (range 0.00-8.00 DC).

various indications for penetrating keratoplasty (Table I).

All patients were receiving first grafts, and all had the same surgical technique using a single continuous adjustable 10/0 nylon suture. Five different surgeons performed the surgery and all the patients were under general anaesthetic. Inferior and superior rectus stay sutures were placed. An ink-stained (eight blade) radial keratotomy marker was used on the host cornea to ensure accuracy in the placement of 'cardinal' alignment sutures. Handheld trephines were used to cut host and donor corneas. Following the four interrupted $10 / 0$ radial graft alignment sutures at 3, 6, 9 and 12 o'clock, a single torsional radial 16 bite 10/0 nylon suture was used to secure the donor button. The suture was then carefully tied with just enough tension to prevent peroperative leakage. The first adjustment was made peroperatively depending on the appearance of the corneal reflection from a hand-held keratoscope.

The initial trial examined the efficacy of a single continuous adjustable suture in penetrating keratoplasty. Adjustment was performed based on a combination of keratometry, refraction, keratoscopy and corneal topography. For values of astigmatism greater than 4.00 dioptre cylinders (DC) adjustment was performed. All adjustments were completed by 32 weeks. Seventeen patients had suture adjustment and 13 did not. The patients who were adjusted showed a median astigmatism of $6.00 \mathrm{DC}$ prior to adjustment and 2.50 DC following adjustment $(p<0.001)$. The final astigmatism for the entire group, both adjusted and non-adjusted, was $2.88 \mathrm{DC}$.

Long-term follow-up of 30 patients from the original group allowed us to report on suture status, time of suture removal, complications, visual acuity and stability of refraction. Suture removal was performed if sutures became loose or broken. Eight patients from the original group were omitted from this study. Of these, 4 patients were lost to follow-up,
1 patient had died, 2 required further surgery (1 trabeculectomy and 1 perforating injury repair) and 1 patient is awaiting a further penetrating keratoplasty following corneal abscess formation and decompensation.

At long-term follow-up the difference in dioptric power of the cylinder from the first study to the second study was termed 'long-term astigmatic drift' (LTAD). This value was expressed as the change in cylinder. A reduction in the dioptric power of the cylinder was felt to occur only by chance and was treated numerically the same as an increase in cylinder. This method of simple analysis of the change in dioptric power of the cylinder does not allow for any change in spherocylindrical equivalent or axis shift. In addition to the subtraction method we have examined the change in astigmatism using vector analysis and vector decomposition (see Appendix). ${ }^{4-10}$

Data were analysed further using non-parametric Mann-Whitney tests, and the Wilcoxon test was used for comparison of overall changes in astigmatism with time.

Table III. Median astigmatism and range of astigmatism with time

\begin{tabular}{lcc}
\hline & \multicolumn{2}{c}{ Astigmatism (DC) } \\
\cline { 2 - 3 } Group & \multicolumn{1}{c}{ Median } & Range \\
\hline Post-keratoplasty & & \\
Adjusted $(n=17)$ & 6.00 & $5.00-9.00$ \\
Non-adjusted $(n=13)$ & 3.00 & $1.00-4.50$ \\
Total $(n=30)$ & 5.00 & $1.00-9.00$ \\
Post-adjustment & & \\
Adjusted $(n=17)$ & 2.50 & $1.00-6.00$ \\
Non-adjusted $(n=13)$ & 3.00 & $1.00-4.50$ \\
Total $(n=30)$ & 2.88 & $1.00-6.00$ \\
Long-term review & & \\
Adjusted $(n=17)$ & 3.00 & $1.00-6.00$ \\
Non-adjusted $(n=13)$ & 3.50 & $0.00-8.00$ \\
Total $(n=30)$ & 3.25 & $0.00-8.00$ \\
\hline
\end{tabular}




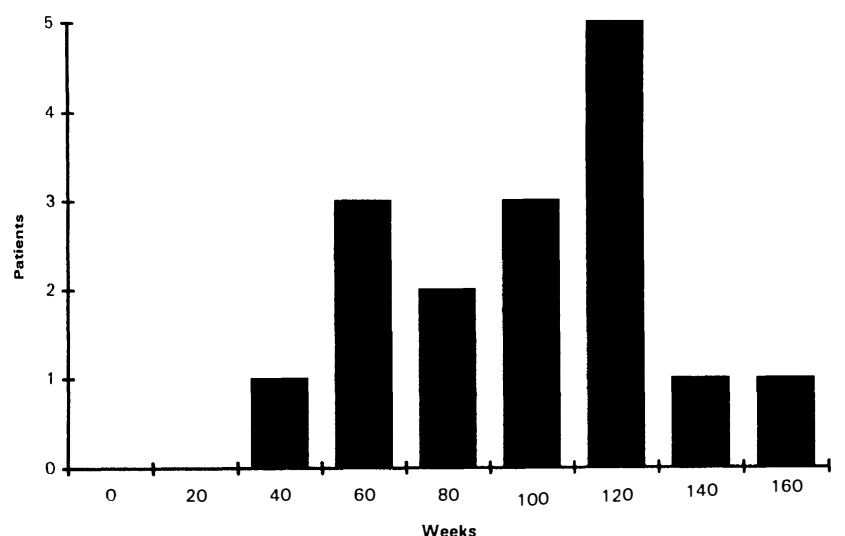

Fig. 1. Chart of suture removal time (weeks) against number of patients.

\section{RESULTS}

The median follow-up for the 30 patients was 112 weeks (range 53-170 weeks) post-keratoplasty. The change in cylinder showed a decrease in 8 patients, remained the same in 2 and increased in 20 patients. The LTAD for the whole group $(n=30)$ revealed significant change. With time, median cylinder postkeratoplasty, or post-adjustment for the adjusted group, changed significantly $(p<0.001)$ from $2.88 \mathrm{DC}$ (range 1.00-6.00 DC) to 3.25 DC (range $0.00-8.00$ DC) (Tables II, III).

Several subgroups were analysed to identify any significant factors influencing LTAD. We compared LTAD in the group with intact sutures, with those who had had suture removal, to see whether suture removal had increased the cylindrical drift. The suture remained intact throughout the study period in 14 patients and was removed in 16 patients. Median LTAD for the intact suture group was 1.00 DC (range 0.00-5.00 DC), and for the group that had suture removal was 1.50 DC (range 0.00-5.50 DC). There was no significant difference between the two groups $(p=0.75)$.

Fig. 1 shows the timing of suture removal. There was no significant difference in the time of suture removal between adjusted and non-adjusted groups $(p=0.43)$. The median time for suture removal for

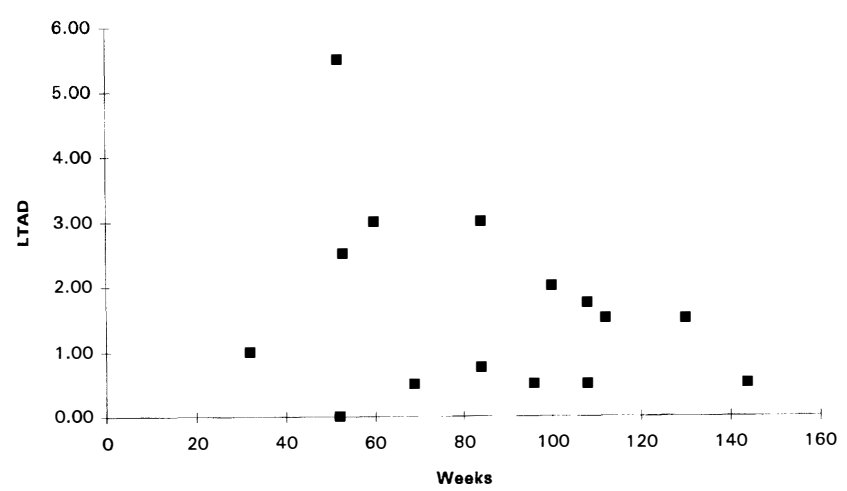

Fig. 2. Scatter plot of long-term astigmatic drift (LTAD) in dioptre cylinders against time of suture removal (weeks).
Table IV. Best corrected visual acuity at follow-up

\begin{tabular}{lc}
\hline Visual acuity & No. of patients \\
\hline $6 / 6$ & 10 \\
$6 / 9$ & 7 \\
$6 / 12$ & 3 \\
$6 / 18$ & 2 \\
$6 / 24$ & 2 \\
$6 / 36$ & 2 \\
$6 / 60$ & 4 \\
Total & 30 \\
\hline
\end{tabular}

the adjusted group was 104 weeks (range 32-144 weeks) and for the non-adjusted group was 76.5 weeks (range 52-130 weeks).

A scatter diagram comparing time of suture removal (median time 90 weeks, range 32-144 weeks) with the amount of LTAD shows a tendency for earlier suture removal to be associated with a great range of drift (Fig. 2). With suture removal between 32 and 84 weeks, median LTAD is 1.50 DC - the same as for suture removal after 84 weeks. In the group with earlier suture removal the range is $5.50 \mathrm{DC}(0.00-5.50 \mathrm{DC})$, while in the group with later removal the range is much smaller at $1.50 \mathrm{DC}(0.50-$ $2.00 \mathrm{DC})$. This is not statistically significant, but requires longer-term review.

We also compared the LTAD between the patients who originally had adjustment $(n=17)$ and those who did not $(n=13)$. The adjusted group showed a median LTAD of 1.00 DC (range 0.00-3.00 DC) and the non-adjusted group a median LTAD of 1.50 DC (range 0.00-5.50 DC). There was no significant difference between these values $(p=0.26)$.

The final visual acuities are shown in Table IV, and the reasons for lowered visual acuity in Table $\mathrm{V}$.

We also analysed our data using vector analysis, using median values for comparison between the groups (Table VI). Calculations for the vector analysis are included in the Appendix. ${ }^{4-10}$

\section{DISCUSSION}

Penetrating keratoplasty is a commonly used surgical procedure for eyes with severe corneal pathology. The use of a single continuous adjustable suture can profoundly reduce post-operative astigmatism, and with its low complication rates is an excellent technique for enhancing surgical outcome following penetrating keratoplasty. ${ }^{1-3}$

Table V. Reasons for visual acuity of less than $6 / 12$ at final follow-up

\begin{tabular}{lc}
\hline Diagnosis & No. of patients \\
\hline Cystoid macular oedema & 4 \\
Age-related macular degeneration & 3 \\
Glaucoma & 1 \\
Graft rejection & 1 \\
Optic atrophy & 1 \\
Total & 10 \\
\hline
\end{tabular}


Table VI. Vector analysis of change in cylinder in dioptres

\begin{tabular}{|c|c|c|c|}
\hline & Not adjusted LTAD & Pre- to post-adjustment & Post-adjustment LTAD \\
\hline $\begin{array}{l}\text { Induced cylinder total vector } \\
\text { Median }\end{array}$ & $3.51 \mathrm{D}$ & $3.70 \mathrm{D}$ & $3.22 \mathrm{D}$ \\
\hline $\begin{array}{l}\text { Induced cylinder against the rule } \\
\text { Median } \\
\text { Standard deviation }\end{array}$ & $\begin{array}{c}1.25 \mathrm{D} \\
\pm 1.28 \\
38.71 \%\end{array}$ & $\begin{array}{c}2.27 \mathrm{D} \\
\pm 2.34 \\
58.41 \%\end{array}$ & $\begin{array}{c}1.49 \mathrm{D} \\
\pm 1.23 \\
35.35 \%\end{array}$ \\
\hline $\begin{array}{l}\text { Induced cylinder with the rule } \\
\text { Median } \\
\text { Standard deviation } \\
\% \text { of total vector }\end{array}$ & $\begin{array}{r}2.26 \mathrm{D} \\
\pm 2.06 \\
61.29 \%\end{array}$ & $\begin{array}{c}1.43 \mathrm{D} \\
\pm 1.53 \\
41.59 \%\end{array}$ & $\begin{array}{c}1.73 \mathrm{D} \\
\pm 1.45 \\
64.65 \%\end{array}$ \\
\hline
\end{tabular}

D, dioptres; LTAD, long-term astigmatic drift.

For methods of calculation see Appendix.

Surgical outcome may be judged both subjectively and objectively. Subjectively, patients' perceptions of their visual function are difficult to quantify. They are dependent not only on the visual function in the grafted eye, but on the comparative function of the fellow eye. Therefore, patients must be carefully selected for penetrating keratoplasty with respect to both the operated eye and the function in the fellow eye. It is well accepted that an eye with a technically successful penetrating keratoplasty but poor visual function in comparison with the fellow eye is unlikely to prove subjectively successful to the recipient. ${ }^{11}$ Objective surgical outcome may be measured in terms of uneventful post-operative recovery, clear cornea, visual acuity and an acceptable refraction in terms of both spherical equivalent and astigmatism.

We have seen from our series that even with careful surgical technique and peroperative 'on table' keratoscopic neutralisation of the cylinder by adjustment, a significant number of patients have unacceptable post-operative astigmatism. Adjustable microsurgical wound closure employing a single continuous suture was first described by RoperHall. ${ }^{12}$ The technique of suturing the graft employing a single adjustable continuous suture is well described. ${ }^{1}$ It allows the surgeon to adjust the suture post-operatively, is performed at the slit lamp, and is eminently reversible. ${ }^{1-3}$ This technique has been shown dramatically to reduce astigmatism (Tables II, III). ${ }^{1,3}$

Many techniques have been used in the management of post-keratoplasty astigmatism, including combinations of interrupted and continuous sutures with interrupted suture removal as well as refractive surgery. ${ }^{13}$ In general these results have been less favourable. We believe the initial large reduction in astigmatism, the ease with which this can be achieved, the paucity of side effects, and the irregular astigmatic control and reversibility make the technique of single continuous adjustable suture the method of choice for post-keratoplasty astigmatism. Our initial results are excellent, and comparable with those experienced by other anterior segment sur- geons. ${ }^{14,15}$ With longer follow-up we have shown that long-term astigmatic drift (LTAD) is to be expected in most patients. Our study has shown a change in median astigmatism with time, from 2.88 DC to 3.25 DC. LTAD is unrelated to a history of suture adjustment. We have seen that even with LTAD most of the problems seem to occur with earlier suture removal, while with long-term suture integrity LTAD is less dramatic, promising better outcome. If a suture is removed after 84 weeks very little shift in astigmatism is seen (Fig. 2). Further follow-up will be required to monitor LTAD. Also, the nature of the radial bite suture is to induce torsional movement in the graft, and this is both seen physically and expressed mathematically by vector analysis. We need to look further at long-term vector stability in terms of methods of placement of torsional or nontorsional suture bites, or combinations of the two, and the effects on stability and outcome.

Clearly, the complex process of corneal healing has a bearing on astigmatism and the support offered by intact sutures in aiding the refractive stability should be borne in mind. Suture removal often follows suture breaks. If this tendency can be reduced by a more permanent suture type, this may reduce LTAD. A possible solution would be to combine the continuous 10/0 nylon, which has proved to be eminently adjustable, with a stabilising continuous $10 / 0$ or $11 / 0$ Mersilene suture, or other more permanent suture. Combinations of two continuous sutures using 10/0 and 11/0 nylon have previously been described. ${ }^{16}$

We previously showed that a signficant reduction in astigmatism occurs with single continuous suture adjustment. ${ }^{3}$ This technique is performed readily at the slit lamp during follow-up and is not associated with any increased risk to the graft. We have demonstrated the need for long-term refractive follow-up post-keratoplasty. We have now shown that there is significant long-term astigmatic drift, and this provides us with a challenge in the long-term management of patients following penetrating keratoplasty. 


\section{APPENDIX. VECTOR ANALYSIS CALCULATIONS}

$\mathrm{DC}_{1}$ and $\mathrm{DC}_{2}$ are taken as primary and secondary cylindrical values in dioptres. Primary cylinder is the initial cylinder and secondary cylinder is the last cylinder measured over time. $\mathrm{DS}_{1}$ and $\mathrm{DS}_{2}$ refer to the spheres, and $\theta_{1}$ and $\theta_{2}$ the axis angle in degrees. Change is represented by $\delta \mathrm{DC}, \delta \mathrm{DS}$ and $\delta \theta$ for cylinder, sphere and axis angle respectively.

1. The subtraction method employed cylindrical values in dioptres:

$$
\delta \mathrm{DC}=\mathrm{DC}_{2}-\mathrm{DC}_{1}
$$

where all cylinders are positive and a decrease in the dioptric power of the cylinder with time is also expressed as its positive value. This gives a range of plus values that are independent of a chance decrease in dioptric cylinder with time, and allows long-term astigmatic drift (LTAD) to be examined numerically.

2. Vector analysis is used to estimate the resultant vertical and horizontal shift patterns, along with axis shift.

Vector components for $\mathrm{DC}_{1}$ and $\mathrm{DC}_{2}$ at $0^{\circ}$ and $45^{\circ}$ are:

$$
\begin{aligned}
& \mathrm{DC}_{1} 0^{\circ}=\mathrm{DC}_{1}\left(\cos 2 . \theta_{1}\right) \\
& \mathrm{DC}_{1} 45^{\circ}=\mathrm{DC}_{1}\left(\sin 2 . \theta_{1}\right) \\
& \mathrm{DC}_{2} 0^{\circ}=\mathrm{DC}_{2}\left(\cos 2 . \theta_{2}\right) \\
& \mathrm{DC}_{2} 45^{\circ}=\mathrm{DC}_{2}\left(\sin 2 . \theta_{2}\right)
\end{aligned}
$$

And to calculate the change:

$$
\delta \mathrm{DC}=\sqrt{ }\left[\left(\mathrm{DC}_{1} 0^{\circ}+\mathrm{DC}_{2} 0^{\circ}\right)^{2}+\left(\mathrm{DC}_{1} 45^{\circ}+\mathrm{DC}_{2} 45^{\circ}\right)^{2}\right]
$$

The resultant axis is calculated by

$$
\delta \theta=0.5 \arctan \left[\left(\mathrm{DC}_{1} 45^{\circ}+\mathrm{DC}_{2} 45^{\circ}\right) \div\left(\mathrm{DC}_{1} 0^{\circ}+\mathrm{DC}_{2} 0^{\circ}\right)\right]
$$

The following conditions apply:

(a) If $\left(\mathrm{DC}_{1} 0^{\circ}+\mathrm{DC}_{2} 0^{\circ}\right)=0$, then $\delta \theta=90^{\circ}$.

(b) If $\left(\mathrm{DC}_{1} 0^{\circ}+\mathrm{DC}_{2} 0^{\circ}\right)<0$, then $\delta \theta$ is increased by adding $90^{\circ}$.

(c) If $\delta \theta>180^{\circ}, \delta \theta$ is reduced by subtracting $180^{\circ}$.

To calculate the horizontal $\left(\delta \mathrm{DC}_{\mathrm{H}}\right)$ and vertical $\left(\delta \mathrm{DC}_{\mathrm{V}}\right)$ components of the induced cylinder:

$$
\begin{aligned}
& \delta \mathrm{DC}_{\mathrm{H}}=\delta \mathrm{DC}\left[\cos ^{2}(\delta \theta)\right] \\
& \delta \mathrm{DC}_{\mathrm{V}}=\delta \mathrm{DC}\left[\sin ^{2}(\delta \theta)\right]
\end{aligned}
$$

These are represented as a percentage of the total change.

The authors wish to thank Helen Jones, Birmingham University Academic Unit of Ophthalmology, for help with statistical analysis.

Key words: Astigmatism, Corneal transplant, Long-term astigmatic drift, Penetrating keratoplasty, Vector analysis.

\section{REFERENCES}

1. McNeill JI, Wessels IF. Adjustment of a single continuous suture to control astigmatism after penetrating keratoplasty. Refract Corneal Surg 1989;5: 216-23.

2. McNeill JI. Long term effects from suture adjustments. Ocular Surg News 1993;[Nov]:19.

3. Hope-Ross MW, McDonnell PJ, Corridan PG, et al. The management of post-keratoplasty astigmatism by post-operative adjustment of a single continuous suture. Eye 1993;7:625-8.

4. Olsen T, Dam-Johansen M. Evaluating surgically induced astigmatism. J Cataract Refract Surg 1994;20:517-22.

5. Naylor EJ. Astigmatic difference in refractive error. $\mathrm{Br}$ J Ophthalmol 1968;52:422-4.

6. Cravy TV. Calculation of the change in corneal astigmatism following cataract extraction. Ophthalmic Surg 1979;10:38-49.

7. Naeser K. Conversion of keratometer readings to polar values. J Cataract Refract Surg 1990;16:741-5.

8. Holladay JT, Cravy TV, Koch DD. Calculating the surgically induced refractive change following ocular surgery. J Cataract Refract Surg 1992;18:429-43.

9. Dam-Johansen M, Olsen T, Theodorsen F. The longterm course of the surgically-induced astigmatism after a scleral tunnel incision. Eur J Implant Refract Surg 1994;6:337-43.

10. Stroud KA. Engineering mathematics, 3rd ed. London: Macmillan Press, 1987.

11. Coster DJ. Doyne Lecture. Influences on the development of corneal transplantation. Eye 1994;8:1-11.

12. Roper-Hall MJ. Control of astigmatism after surgery and trauma. Br J Ophthalmol 1982;66:556-9.

13. Kirkness CM, Ficker LA, Steele AD, Rice NSC. The success of penetrating keratoplasty for keratoconus. Eye 1990;4:673-88.

14. Binder PS. Selective suture removal can reduce postkeratoplasty astigmatism. Ophthalmology 1985; 92:1412-6.

15. Belmont SC, Troutman RC, Buzard KA. Control of astigmatism aided by intraoperative keratometry. Cornea 1993;12:397-400.

16. Clinch TE, Thompson HW, Bradley PB, et al. An adjustable double running suture technique for keratoplasty. Am J Ophthalmol 1993;116:201-6. 